\title{
LEGISLANDO EN LA OSCURIDAD. EL CASO DEL CONTROL DE IDENTIDAD PREVENTIVO Y SU DEBATE EN LA CÁMARA DE DIPUTADOS*
}

\author{
Mauricio Duce \\ Universidad Diego Portales
}

\begin{abstract}
Resumen: El objetivo de este artículo es analizar de manera crítica el debate sobre el proyecto de ley destinado a ampliar las facultades de las policías para realizar controles de identidad preventivos que fue aprobado por la Cámara de Diputados en septiembre de 2015. Para ello, se realiza un análisis de los fundamentos que plantearon sus partidarios durante la tramitación legislativa. Este estudio da cuenta de una propuesta elaborada con desconocimiento de la evidencia empírica disponible y sustentada en serios errores y prejuicios. Todo esto muestra una baja calidad del debate legislativo y permite argüir que se trata de una reforma innecesaria, a la luz de las justificaciones que sus partidarios invocan, e inconveniente, por los riesgos que genera al ejercicio de derechos fundamentales de nuestros ciudadanos.

PAlABRAS ClAVE: control de identidad, control de identidad preventivo, facultades policiales, debate legislativo, derechos fundamentales.

RECIBIDO: octubre 2015; ACEPTADO: diciembre 2015.
\end{abstract}

Mauricio Duce. Licenciado en ciencias jurídicas por la Universidad Diego Portales. Abogado y magíster en ciencias jurídicas por la Universidad de Stanford. Profesor titular de la Facultad de Derecho Universidad Diego Portales. Email: mauricio. duce@udp.cl

* El autor quiere agradecer los comentarios realizados por los evaluadores anónimos de Estudios Públicos. 


\title{
LEGISLATING IN THE DARKNESS: THE CASE OF THE PREVENTIVE IDENTITY CHECK AND ITS DEBATE IN THE DEPUTIES CHAMBER
}

\begin{abstract}
The paper's objective is to make a critical assessment of the debate regarding the bill that regulate a power that allows the police to make a preventive identity check that was adopted by the Deputies Chamber on September 2015. In that direction the paper makes an analysis of the arguments presented by the supporters of this idea. The analysis concludes that the project is constructed without considering the available empirical evidence and it is based on serious mistakes and prejudices. This shows the low quality of our legislative debate and allows to conclude that it is an unnecessary reform in light of its justifications and also inconvenient because of the risk that creates in the exercise of the fundamental rights of our citizens.
\end{abstract}

KEYWORDS: identity check, stop and frisk, preventive identity check, police powers, legislative debate, fundamental rights.

RECEIVED: October 2015; ACCEPTED: December 2015.

\section{INTRODUCCIÓN}

esde hace algún tiempo, la seguridad ciudadana se ha convertido en una de las principales — cuando no la central— preocupaciones de la ciudadanía. ${ }^{1}$ Esta situación ha motivado el surgimiento de un conjunto de iniciativas legales destinadas a favorecer la persecución y sanción de los delitos. Dentro de ellas, una de las ideas que han estado presente con mayor fuerza en el debate público ha sido la de instaurar en nuestro país una facultad que permita a los funcionarios policiales solicitar la identificación de cualquier persona con fines preventivos. Esta facultad es la que se conoce como "control de identidad preventivo". Más allá de que lo que finalmente resulte de la discusión parla-

${ }^{1}$ La Encuesta Nacional de Opinión Pública de agosto de 2015, del Centro de Estudios Públicos (CEP), muestra que frente a la pregunta "¿Cuáles son los tres problemas a que debería dedicar mayor esfuerzo en solucionar el Gobierno?", la respuesta que ocupa el primer lugar con el 60 por ciento de menciones es "Delincuencia, asaltos, robos". En la encuesta del mes de abril de 2015, dicha respuesta también ocupaba el primer lugar, pero con el 46 por ciento de las menciones. Centro de Estudios Públicos, "Encuesta Nacional de Opinión Pública de agosto de 2015", en http://www.cepchile.cl/dms/archivo_6053_3756/EncuestaCEP_Agosto2015.pdf. 
mentaria en curso al editarse este artículo, en ella han surgido puntos de vistas y argumentos que merecen ser analizados en forma independiente de los resultados finales con que concluya el proceso legislativo. ${ }^{2}$

Al menos tres proyectos de reforma legal se han presentado en los últimos años en la misma dirección. En julio de 2013, el gobierno de Sebastián Piñera envió un proyecto al Senado de la República, proponiendo un nuevo artículo 3 bis a la Ley n. ${ }^{\circ} 18.961$ (“Ley orgánico constitucional de Carabineros de Chile") para establecer la facultad de control de identidad preventivo en manos de Carabineros. ${ }^{3}$ A pesar de su impulso inicial, se trata de una moción que no ha prosperado a la fecha. Seguramente esto explica que sólo 14 meses después, el 10 de septiembre de 2014, los senadores de la UDI Van Rysselberghe, Coloma y Pérez presentaran un nuevo proyecto de ley con el mismo propósito, pero ahora destinado a establecer un "control de identidad precautorio de Carabineros de Chile". Este proyecto también plantea regular un nuevo artículo 3 bis a la Ley $\mathrm{n}^{\mathrm{o}} 18.961$ y su contenido es idéntico a la iniciativa presentada el año 2013, cambiando sólo algunos elementos menores en su fundamentación y en el lenguaje utilizado en la regla propuesta. Tampoco se trata de una moción que haya tenido algún avance relevante luego de presentada.

La última de estas iniciativas se produjo en 2015. Así, el 6 de mayo, en el contexto de discusión de un proyecto de ley destinado a regular temas de seguridad pública ${ }^{4}$ — que fue conocido en los medios como "agenda corta" o "agenda corta antidelincuencia"-, la Comisión

${ }^{2} \mathrm{Al}$ recaer mi análisis sobre un proyecto de ley en tramitación al momento de concluirse este texto es posible prever que será objeto de cambios y variaciones. Como se podrá apreciar en el desarrollo del texto, el artículo se focaliza en el análisis de argumentos y de un tipo de trabajo legislativo que va más allá del contenido específico de la propuesta; por lo mismo, esos potenciales cambios no debieran alterar los puntos aquí desarrollados ni su relevancia para el debate de políticas públicas. En todo caso, para los efectos de la norma en análisis, se trabaja con la versión aprobada por la Cámara de Diputados el 9 de septiembre de 2015, que corresponde al último texto oficial disponible al momento de entregar este artículo.

${ }^{3}$ Presidencia de la República, "Mensaje de S. E. Presidente de la República, con el que inicia un Proyecto de Ley que establece el control preventivo de identidad por parte de Carabineros de Chile", Mensaje n. ${ }^{\circ}$ 137-361, 10 de julio de 2013.

${ }^{4}$ Presidencia de la República, "Mensaje de S. E. la Presidente de la República con el que se inicia un Proyecto de Ley que facilita la aplicación efectiva de las penas establecidas para los delitos de robo, hurto y receptación y mejora la persecución penal en dichos delitos", Mensaje n. ${ }^{\circ}$ 1167-362, presentado a la Cámara de Diputados el 23 de enero de 2015. Boletín n. ${ }^{\circ}$ 9885-07 de la Cámara de Diputados. 
de Seguridad Ciudadana de la Cámara de Diputados aprobó (siete votos contra seis) una indicación presentada por la diputada Nogueira y los diputados Coloma, Farcas, Fuenzalida, Sabat, Silber y Squella para incorporar al Código Procesal Penal (en adelante CPP) un nuevo artículo 85 bis, en el que se plantea una versión remozada del control de identidad preventivo de los dos proyectos previos. ${ }^{5}$ Esta iniciativa fue objeto de un debate intenso que llevó incluso a que el Ejecutivo elaborara una indicación en el trámite ante la Comisión de Constitución, Legislación, Justicia y Reglamento de la Cámara de Diputados. Finalmente, con varios cambios respecto a la propuesta original, el texto fue aprobado por la Cámara de Diputados el día 9 de septiembre de 2015 . $^{6}$

Como se puede apreciar, la idea de legislar sobre el control de identidad preventivo ha llegado para quedarse, por lo que más temprano que tarde se puede esperar que esta facultad sea finalmente objeto de algún tipo de regulación normativa en nuestro país. ${ }^{7}$

Las ideas expresadas a lo largo de la tramitación de esta propuesta en la Cámara de Diputados dan cuenta de los problemas de calidad que tiene en nuestro país la discusión legislativa de proyectos en materia de seguridad ciudadana. Lamentablemente, se trata de un problema transversal, es decir, que no es propio de un partido o sector político, y que

${ }^{5}$ Comisión de Seguridad Ciudadana Cámara de Diputados, “Acta sesión $41^{\text {a }}$ ordinaria correspondiente a la $363^{\text {a }}$ legislatura del miércoles 6 de mayo de 2015", en http://www.camara.cl/pdf.aspx?prmID=18936\&prmTIPO=ACTACOMISION. Votaron a favor las diputadas Nogueira y Sabat y los diputados Coloma, Farcas, Fuenzalida, Silber y Squella. En contra, la diputada Cariola y los diputados Ceroni, Jackson, Pilowsky, Soto y Walker.

${ }^{6}$ Cámara de Diputados, "Oficio n. ${ }^{\circ} 12.091 ”, 9$ de septiembre de 2015 (documento en formato electrónico en poder del autor).

7 Esto, sin perjuicio de que, como veré un poco más adelante, ya ha sido objeto de regulación en nuevas legislaciones especializadas como lo es la Ley n. ${ }^{\circ}$ 19.327. Más allá de esto, el medio ambiente político da cuenta de una enorme demanda por regular una facultad más general en la materia. En esta dirección, el senador Alberto Espina señaló en unas declaraciones vertidas a propósito del funcionamiento del sistema de responsabilidad penal de adolescentes: "Es incomprensible que en nuestro país no exista el control de identidad preventivo". "Espina: fracaso rotundo de la ley penal juvenil", El Mercurio, 27 de julio de 2015. Antes de esto, esta facultad se ha transformado en una de las principales medidas propuestas por senadores de la Alianza por Chile en el contexto de la campaña que han llevado adelante denominada "Juntos por la delincuencia". Véase, "Las 10 medidas que proponen senadores de la Alianza para disminuir la delincuencia", La Tercera, 17 de julio de 2015 . 
parece estar replicándose en todos los debates en el área. ${ }^{8}$ Es por eso que, independientemente del resultado específico que se produzca en la tramitación en el Senado de esta iniciativa en particular, se está ante un caso de estudio representativo de cierta forma de legislar. Llama la atención, por ejemplo, que los debates se conduzcan con desapego de la evidencia empírica disponible. Otro aspecto problemático se da en el uso erróneo del derecho comparado como justificación de cambios legales. Todo esto se traduce en un uso de argumentos deficientes y en proyectos con problemas de fundamentación técnica. Esto es lo que yo llamo legislar en la oscuridad, es decir, legislar sobre la base de intuiciones y prejuicios que pueden generar consecuencias indeseadas y no previstas en el debate.

En ese contexto, este artículo tiene por objeto contribuir a elevar la calidad del debate en materia de reformas legislativas destinadas a mejorar la seguridad ciudadana en nuestro país. Para ello se realizará un análisis crítico de los fundamentos que han planteado, en la Cámara de Diputados, los partidarios de regular el control de identidad preventivo, mostrando los problemas que se presentan en los distintos argumentos planteados. Esto me permitirá concluir que se trata de una reforma innecesaria para lograr los objetivos que la justifican, al mismo tiempo que inconveniente, ya que concede a las policías una facultad muy riesgosa para la vigencia de derechos de nuestros ciudadanos, y constituye una mala idea para potenciar la profesionalización y mejora del trabajo policial en nuestro país.

Para desarrollar estas ideas dividiré el trabajo en cuatro secciones, además de esta introducción. En la primera expondré brevemente el contenido y justificaciones de la actual propuesta aprobada por la Cámara de Diputados. En la segunda, me haré cargo críticamente de las justificaciones esgrimidas a favor de regular esta facultad. En la tercera, abordaré de manera breve algunas de las consecuencias o efectos negativos que una facultad de este tipo podría tener en caso de aprobarse como ley. Finalmente, dejaré una última sección para presentar una breve reflexión de cierre.

\footnotetext{
${ }^{8}$ Un ejemplo de lo mismo se ve en el proyecto de ley denominado "Reforma a la reforma procesal penal", presentado por el Poder Ejecutivo al Senado el 29 de enero de 2013. Un análisis crítico del mismo puede verse en Mauricio Duce, "La 'reforma a la reforma procesal penal': análisis de la gestación y contenidos de un proyecto de ley”, en Anuario de Derecho Público 2013 (Santiago: Ediciones Universidad Diego Portales, 2013), 110-144.
} 


\section{LA PROPUESTA DE ESTABLECER UN CONTROL DE IDENTIDAD PREVENTIVO Y SU JUSTIFICACIÓN}

Como ya señalé en la introducción, el 6 de mayo de 2015 la Comisión de Seguridad Ciudadana de la Cámara de Diputados aprobó una indicación para introducir un nuevo artículo 85 bis para incorporar al $\mathrm{CPP}$, en el que se proponía establecer un control de identidad preventivo. ${ }^{9}$ Esta propuesta generó un intenso debate que concluyó el 9 de septiembre de 2015, cuando la Cámara finalmente aprobó una reforma al estatuto actual de control de identidad vigente con dos tipos de cambios.

El primero consiste en la introducción de reformas al actual control de identidad regulado en el artículo 85 del CPP, que básicamente permiten rebajar el estándar que autoriza a las policías a efectuarlo (en vez de la existencia de "indicios", como establece la actual disposición, el proyecto admite el control cuando hay sólo un "indicio", es decir, mucho menos evidencia) y agrega una hipótesis nueva a la facultad que permite a las policías practicar controles de identidad, permitiendo que ésta se realice también en situaciones en que se estima que una persona podría tener una orden de detención pendiente. ${ }^{10} \mathrm{El}$ impacto natural de estos cambios debiera ser un incremento de las facultades policiales para exigir el control de identidad a las personas.

La segunda reforma —y se trata de la principal— está constituida por la inclusión del artículo 12 del proyecto, que regula derechamente

${ }^{9}$ El contenido exacto de esta propuesta era el siguiente: "Artículo 85 bis.Control de identidad preventivo. Sin perjuicio de lo establecido en el artículo anterior, en el ejercicio de su rol preventivo, las policías a través de su personal en servicio, podrán solicitar la identificación de cualquier persona para cotejar la existencia de órdenes de detención pendientes. / La identificación se realizará en el lugar en que la persona se encontrare, por medio de documentos de identificación expedidos por la autoridad pública, como cédula de identidad, licencia de conducir y pasaporte, o por cualquier otro medio verosímil que permita establecer positivamente su identidad. El funcionario policial deberá otorgar a la persona las facilidades para identificarse. / En caso de negativa de una persona a acreditar su identidad, se aplicará lo establecido en los incisos tercero y siguientes del artículo anterior. / El abuso en el ejercicio de las facultades establecidas en este artículo por parte de las policías estará sujeto a las sanciones administrativas y penales que correspondan".

${ }^{10}$ En esta dirección se agrega un inciso que señala textualmente: "Procederá también tal solicitud cuando los funcionarios policiales tengan algún antecedente que les permita inferir que una determinada persona tiene alguna orden de detención pendiente". 
el control de identidad preventivo y reemplazaría al artículo 85 bis del CPP que originalmente había sido propuesto en la Comisión de Seguridad Ciudadana de la Cámara. En su hipótesis central la regla señala:

Artículo 12.- En cumplimiento de las funciones de resguardo del orden y la seguridad pública, y sin perjuicio de lo señalado en el artículo 85 del Código Procesal Penal, los funcionarios policiales señalados en el artículo 83 del mismo Código podrán controlar la identidad de cualquier persona en el lugar en que se encontrare, por cualquier medio de identificación expedido por la autoridad pública, como cédula de identidad, licencia de conducir y pasaporte. El funcionario policial deberá otorgar a la persona las facilidades para identificarse.

Me detengo brevemente. En lo que constituye su núcleo básico, esta norma facultaría a los policías para solicitar la identificación de cualquier persona que ellos estimen conveniente, sin ningún requisito o exigencia. Es decir, la ley no fijaría ningún estándar para limitar la facultad de exigir identificación. Desde este punto de vista, ello corresponde a una flexibilización total del actual artículo 85 del CPP, el cual concede esta facultad pero sólo bajo ciertas hipótesis determinadas, como se verá en la próxima sección.

La norma aprobada regula también lo que ocurre en casos en que el procedimiento no pueda llevarse a efecto por imposibilidad de identificación en el mismo lugar. Así, cuando la persona requerida por los funcionarios policiales no cuente en ese momento con documentos públicos de identificación disponibles ("medio de identificación expedido por la autoridad pública"), debe ser llevada y retenida en un recinto policial hasta por un máximo de cuatro horas para efectos de procurar su identificación (en la propuesta original se trataba de un máximo de ocho horas, equivalente al de la regla contenida en el artículo 85 del CPP vigente). En todo caso, este último procedimiento tendría lugar cuando se trate de personas que se nieguen a acreditar su identidad. Sin ser completamente clara sobre el punto, ya que no se pronuncia de manera explícita sobre la materia, la norma permitiría eventualmente también hacer un registro de vestimentas de las personas cuya identificación es requerida (potencialmente también de los equipajes que portare o del vehículo que condujere en su caso), según explicaré más adelante. 
Junto con lo anterior, en la norma aprobada por la Cámara se determina un conjunto de reglas para favorecer que el uso de esta nueva facultad policial se haga respetando la igualdad de trato y no discriminación de los controlados y estableciendo un sistema de reclamos cuando las personas afectadas consideren que su ejercicio ha sido abusivo. Finalmente, se contemplan también varias disposiciones que determinan un deber de registro de las policías de los reclamos efectuados y la obligación de generar y luego entregar periódicamente estadísticas sobre el uso de la facultad, de manera de permitir el control en su ejercicio de parte de las autoridades y, eventualmente, de la comunidad. ${ }^{11}$

Las justificaciones que se han esgrimido para apoyar este cambio son diversas y son bastante similares a las invocadas a propósito del proyecto del año 2013 y del año $2014 .{ }^{12}$ Paso revista brevemente a las principales que se han formulado en la actual discusión.

11 Reproduzco los incisos dos a ocho del texto aprobado por la Cámara, en donde se puede revisar con mayor detalle el alcance de estas normas: "En la práctica de la identificación se deberán respetar la igualdad de trato y no discriminación arbitraria. / En el ejercicio de esta facultad los funcionarios policiales deberán exhibir su placa e identificarse. Si la persona se niega a acreditar su identidad o si habiendo recibido las facilidades del caso no le fuere posible hacerlo, la policía la conducirá a la unidad policial más cercana para fines de identificación. / El conjunto de procedimientos detallados precedentemente no deberá extenderse por más de cuatro horas, transcurridas las cuales deberá ser puesta en libertad. En caso de que la persona mantenga órdenes de detención pendientes, la policía procederá a su detención, de conformidad a lo establecido en el artículo 129 del Código Procesal Penal. / Las Policías deberán elaborar un procedimiento estandarizado de reclamo para ser implementado en cada unidad policial, que permita a aquellas personas que estimaren haber sido objeto del ejercicio arbitrario del control de identidad del presente artículo, formular su reclamo de conformidad con las normas administrativas, sin perjuicio de la responsabilidad penal que procediere. / Además, dichas instituciones deberán publicar bimensualmente en su página web estadísticas de la cantidad de reclamos formulados en virtud del inciso anterior, desagregada por sexo, edad y nacionalidad. La misma información, además de los avances y resultados de dichos reclamos, deberá ser remitida al Ministerio del Interior y Seguridad Pública. / También deberán publicar semestralmente el número de controles de identidad practicados en virtud del presente artículo, desagregados por sexo, edad y nacionalidad. / Junto con lo anterior, a lo menos semestralmente las Policías deberán dar cuenta al Ministerio del Interior y Seguridad Pública de la frecuencia y lugares en que se concentra la mayor cantidad de controles de identidad por sexo, edad y nacionalidad. Asimismo, deberán informar la cantidad de detenciones por flagrancia que dieren origen en virtud de su práctica, desagregada por tipo de delito y las variables antes señaladas, de conformidad a lo dispuesto en la Ley n. ${ }^{\circ} 20.502$ ”.

12 Por ejemplo, Presidencia de la República, "Mensaje n. ${ }^{\circ}$ 137-361", 10 de julio de 2013, 4-7. 
Durante el debate en la Comisión de Seguridad Ciudadana del mes de mayo de 2015 los diputados Nogueira y Fuenzalida, quienes se han mostrado muy activos en la defensa de la idea de legislar, pusieron especial énfasis en que este proyecto sería una necesidad por la existencia de más de 66 mil órdenes de detención pendientes, que requerirían de una facultad específica para ser cumplidas. ${ }^{13}$ En ese contexto, además, se ha sostenido que el actual artículo 85 del CPP contendría hipótesis "absolutamente restrictivas" para el trabajo de las policías, lo que les impediría controlar eficazmente esas órdenes de detención pendientes. ${ }^{14}$ Las justificaciones también consideran que la redacción actual del artículo 85 del CPP produciría situaciones de indeterminación que han generado problemas de interpretación en sede judicial. ${ }^{15}$ Estas ideas son resumidas por el diputado Fuenzalida en una entrevista en La Tercera, en la que señala: "El control de identidad que tenemos no sirve, es por eso que hoy más nunca es primordial establecer el control de identidad preventivo". ${ }^{16}$

Las anteriores justificaciones se han complementado señalando que los controles de identidad preventivos serían una facultad comúnmente reconocida en el ámbito del derecho comparado, sugiriendo de esta forma que en Chile nos privaríamos de una herramienta significativa para la prevención de los delitos. ${ }^{17}$ Finalmente, haciéndose cargo de poten-

${ }^{13}$ Comisión de Seguridad Ciudadana Cámara de Diputados, "Acta Sesión $41^{\mathrm{a}}$ ordinaria correspondiente a la $363^{\text {a }}$ legislatura del miércoles 6 de mayo de 2015”, 6 , en http://www.camara.cl/pdf.aspx?prmID=18936\&prmTIPO=ACTACOMISION. Se trata de un argumento manifestado permanentemente en el debate público por los promotores de esta iniciativa. Así, por ejemplo, el diputado Farcas lo señala en una carta publicada en la sección e-pístolas de El Mostrador, el 2 de septiembre de 2015: "Control de identidad preventivo: ¿detención por sospecha?”.

${ }^{14}$ En este sentido se pronuncia la diputada Nogueira en una carta publicada en La Tercera sobre la materia. "Control de identidad", La Tercera, 25 de mayo de 2015. El diputado Fuenzalida, en esta misma línea, sostiene en una carta publicada en El Mercurio que el proyecto se justifica, ya que "Carabineros no cuenta con las herramientas necesarias para su labor preventiva". "Control preventivo de identidad", El Mercurio, 29 de mayo de 2015, A2.

${ }^{15}$ En esta línea apunta la diputada Nogueira explícitamente en su carta publicada en La Tercera sobre la materia citada en la nota anterior.

16 "Justicia anuncia aumento de pena por agresiones a Carabineros", La Terce$r a, 25$ de julio de 2015 .

${ }^{17}$ El diputado Fuenzalida argumenta invocando ejemplos como el de Alemania, Estados Unidos o Italia. "Según estudios varios países de la OCDE aprueban leyes sobre control de identidad", La Segunda, 24 de junio de 2014. Haciendo un argumento más general pero similar puede verse en la carta ya citada de la diputada Nogueira, "Control de identidad". En la misma línea, repite su posición en una carta de 2 de junio de 2015. "Control de identidad", La Tercera. 
ciales críticas sobre los efectos de establecer una facultad de este tipo, algunos de sus defensores han sostenido que ella supondría una "carga ciudadana menor"18 y que no debiera generar preocupación ciudadana, ya que "quien nada hace, nada debe temer". ${ }^{19}$

Sus propulsores justifican también la necesidad de regular esta facultad en la medida en que ella le concedería a la policía una herramienta clave para mejorar sus capacidades de prevenir y sancionar los delitos, especialmente en un contexto que caracterizan como muy grave desde el punto de vista de la seguridad pública. ${ }^{20}$

En suma, los propulsores de esta iniciativa han intentado instalar la noción que se trata de una reforma indispensable para la seguridad ciudadana, inocua desde el punto de vista de los derechos ciudadanos y ampliamente reconocida en el derecho comparado.

\section{LAS DEBILIDADES EN LA JUSTIFICACIÓN DE ESTA REFORMA LEGAL}

En lo que sigue ofreceré razones para sostener que las argumentaciones entregadas para justificar la regulación de un control de identidad preventivo son extremadamente débiles y, peor aún, se basan en

${ }^{18}$ En palabras de la diputada Nogueira, con esta facultad “... lo único que se podría contener como limitación a la libertad de las personas es algo tan simple como que Carabineros pueda solicitar su identificación". Ver "Control" (25 de mayo). Apoyando esta idea y utilizando la expresión "carga ciudadana menor" se pronuncia un editorial de La Tercera, "Identificación preventiva y policías municipales", 20 de mayo de 2015.

19 Máximo Pavez, "El que nada hace...", La Tercera, 23 de mayo de 2015. Insistiendo en esta misma dirección, véase Máximo Pavez, "Control de identidad preventivo: ¿por qué temer?”, La Tercera, 25 de agosto de 2015.

${ }^{20}$ Por ejemplo, la diputada Nogueira ha señalado claramente pensando desde esta perspectiva: "Si consideramos que el Índice Paz Ciudadana Adimark de 2014 señala que las víctimas de delitos llegan a un 43,5 por ciento en el país - siendo el índice más alto desde el año 2000 — y que actualmente hay cerca de 66.041 órdenes de detención pendientes, parece necesario dotar de mayores atribuciones a Carabineros, que les permitan tener más eficacia en su rol de policía preventiva”. Ver "Control" (2 de junio). En esta dirección también parece pronunciarse el subsecretario de prevención del delito, Antonio Frey, quien en una columna publicada en $\mathrm{El}$ Mostrador destaca que el control de identidad preventivo debiera tener un impacto positivo en la prevención de los delitos. Antonio Frey, "Control de identidad preventivo: más seguridad sin vulnerar los derechos de las personas", El Mostrador, 19 de septiembre de 2015 . 
supuestos erróneos, tanto fácticos como jurídicos. Me detendré en los principales argumentos revisados en la sección anterior. Esto permitirá identificar los defectos que ha tenido el debate legislativo en la Cámara de Diputados, lo que genera dudas acerca de la comprensión de los alcances de esta propuesta que tuvieron quienes prestaron su voto al momento de aprobarla.

\section{1. ¿Cuentan las policias con facultades de control de identidad preventivo en la actualidad?}

Como ya señalaba, una primera línea esbozada por quienes proponen este proyecto se basa en la idea de que en la actualidad las policías no disponen de facultades legales preventivas o que éstas son mínimas. $^{21}$

El problema es que este argumento desconoce que en Chile ya existe la posibilidad de realizar un control de identidad y, además, en casos "preventivos". Es más, se trata de facultades bastante amplias previstas en nuestra legislación. Parto por revisar la norma básica en la materia. El actual artículo 85 del CPP permite a las policías solicitar identificación no sólo en hipótesis en donde existen indicios de que una persona ha cometido o intentado cometer delitos (entendido en forma amplia, ya que incluye crímenes, simples delitos y faltas), sino también toda vez que se estime que "se dispone" a cometerlo o que pueda "tener información útil" para la indagación de un delito, lo que abre enormemente el ámbito de procedencia del control. Por si fuera poco, a ello se agrega la posibilidad de ejercer este control respecto de toda persona que se "encapuche o emboce para ocultar, dificultar o disimular su identidad."

Tan sólo por su tenor literal, se puede apreciar que se trata de una facultad bastante amplia y que cubre casos en donde las personas no

${ }^{21}$ Esta línea ha sido insistida por Carabineros en el trámite legislativo de esta iniciativa. Así, en la sesión del 15 de julio de 2015 realizada por la Comisión de Constitución, Legislación y Justicia de la Cámara de Diputados, el coronel Elgueta sostuvo: “...el actual artículo sólo alcanza un limitado número de casos. En esta propuesta, se busca reforzar un rol fundamental de Carabineros, vinculado con la prevención”. Comisión de Constitución, Legislación, Justicia y Reglamento, “Acta de la $114^{a}$ sesión", 15 de julio de 2015, 7, en http://www.camara.cl/pdf.aspx?prmID $=19318 \&$ prmTIPO $=$ ACTACOMISION. 
han cometido delito alguno e incluso situaciones en las que no hay una imputación en contra de ellas (por ejemplo cuando se tiene información útil). Un caso evidente de esto se da en la hipótesis en donde se permite a las policías intervenir respecto de quien se dispone a cometer el delito, es decir, como forma clara para prevenir su ocurrencia. En esta dirección, la hipótesis más paradigmática es la regla que permite el control de identidad respecto de quien está encapuchado o embozado. Ella claramente regula lo que podría ser identificado como una hipótesis objetiva destinada a la prevención, ya que no supone ninguna comisión actual de delito. En efecto, el legislador presume que el encapuchado presenta un cierto riesgo en todo evento, lo que faculta a las policías para realizar un control de identidad que incluso les permite retener a la persona hasta por ocho horas.

Se trata, en definitiva, de una norma con importantes espacios para el trabajo preventivo policial. De hecho, la revisión de su historia legislativa da cuenta de que una de las finalidades al introducir esta norma fue precisamente la de entregarles a las policías facultades preventivas de intervención..$^{22}$ Por si fuera poco, el artículo 85 del CPP ha sido reformado en diversas ocasiones con el objeto preciso de delimitar sus alcances y flexibilizar su uso, y darle así mayores atribuciones a las policías en esa dirección. En efecto, la revisión de la historia de las distintas reformas que ha sufrido esta norma lleva claramente a esta conclusión. La primera de éstas fue realizada por la Ley $\mathrm{n}^{\circ}$ 19.789, de enero de 2002; luego por la Ley n. ${ }^{\circ} 19.942$, de abril de 2004, y finalmente por la Ley n. ${ }^{\circ} 20.253$, de marzo de $2008 .^{23}$

22 En esta dirección, véase Paz Irarrázabal, "Igualdad en Chile: el caso del control de identidad”, Revista Política Criminal 10, n. ${ }^{\circ} 19$ (julio 2015): 236-242.

${ }^{23}$ Sobre la evolución legislativa del control de identidad analizando con detalles los contenidos de sus diversas reformas, se puede ver Jaime Salas, "Evolución del control de identidad. ¿En ruta a su desnaturalización?”, en Problemas del Proceso Penal (Santiago: Librotecnia, 2015), 161. Véase también Roberto Rabi, “QQué rol y justificación tiene el control de identidad de una persona en nuestro sistema procesal penal considerando el actual texto del artículo 85 del Código Procesal Penal", Revista Estudios de la Justicia 13 (2010): 323-363, especialmente 325-333. Mostrando con especial énfasis el reforzamiento de las funciones preventivas de esta institución a partir de sus reformas, véase César Ramos, "Control de identidad. Bases para una aplicación diferenciada del artículo 85 del Código Procesal Penal", en Diez años de la reforma procesal penal en Chile (Santiago: Ediciones Universidad Diego Portales, 2011), 577-608, especialmente 581-593. 
A lo anterior, se suma que en forma reciente (junio de 2015) fue aprobada una nueva versión de la Ley n. 19.327 (“de derechos y deberes en los espectáculos de fútbol profesional"), que establece en su artículo 21 inciso cuarto una norma de control de identidad preventivo puro y duro en el contexto de realización de espectáculos de fútbol profesional, incrementando de manera significativa las facultades de este tipo previstas en la legislación vigente. Así, dicha norma establece:

El personal de Carabineros de Chile podrá efectuar controles de identidad preventivos, con las facultades contempladas en el artículo 85 del Código Procesal Penal, en los recintos deportivos o sus inmediaciones, desde una hora antes de que se abran las puertas del establecimiento, durante la realización de un espectáculo de fútbol profesional y hasta tres horas después de su término.

Como se puede apreciar, esta norma entonces amplía de manera significativa las facultades del artículo 85 del CPP y debiera traducirse en un incremento del total de controles en los próximos años. ${ }^{24}$

En consecuencia, si se considera la amplitud del actual artículo 85 del CPP y su reforzamiento normativo reciente (artículo 21, Ley n. ${ }^{\circ}$ 19.327), parece bastante dudoso afirmar que en la actualidad los organismos policiales no tengan facultades preventivas de control de identidad. Esto ya arroja serias dudas acerca de la corrección del fundamento base de esta iniciativa. En la práctica, Carabineros parece entender que efectivamente las normas en estudio le permiten organizar operaciones de carácter preventivo bastante amplias. Así, en una cuenta pública realizada por el general de Carabineros Gonzalo Blu (director de Inteligencia, Drogas e Investigación Criminal), respecto a las metas antidelincuencia establecidas por el director general de la institución en julio de 2015, se declara haber organizado en los dos meses siguientes siete operativos de control preventivo y de orden y seguridad, que permitieron detener a 1.714 personas por delitos fla-

${ }^{24}$ Cabe señalar que, a diferencia de la norma aprobada en el proyecto en análisis que establece una facultad sin límites para las policías, el artículo 21 de la Ley n. ${ }^{\circ} 19.327$ restringe la facultad policial temporal y espacialmente. Desde una perspectiva temporal, ella se puede ejercer dentro del período de una hora antes y tres después de la realización de un partido de fútbol. Espacialmente, ella se limita al recinto deportivo y sus inmediaciones. 
grantes. ${ }^{25}$ Es decir, Carabineros, con las normas actuales, puede perfectamente hacer actividad preventiva de control con alto impacto en la detención de delitos.

\section{2. ¿El actual artículo 85 del CPP es realmente ineficaz?}

En este escenario, en donde hay normas que establecen facultades a las policías razonablemente amplias para controlar la identidad, se argumenta entonces que el conflicto en la práctica se produciría como consecuencia de un conjunto de problemas interpretativos que genera esta facultad en sede judicial, producto de la redacción del artículo 85 del CPP y de sus exigencias, todo lo cual justificaría la aprobación de una nueva regla que supere tales problemas interpretativos.

A partir de esta línea argumental se suele sugerir que las policías tienen, en la práctica, atadas sus manos frente a la persistente declaración de ilegalidades que harían los jueces de garantía de las detenciones por flagrancia originadas a partir de los controles de identidad. La norma propuesta vendría entonces a superar un problema de diseño normativo, que impone una práctica de restricciones y limitaciones excesivas al trabajo policial. ${ }^{26}$ En esta dirección se entiende la declaración ya citada del diputado Fuenzalida, cuando señalaba que el actual control de identidad "no sirve".

Como se puede observar, toda esta línea argumental descansa sobre la base de un diagnóstico acerca del comportamiento de la realidad. Por

25 "Carabineros afirma que desactivó 77 bandas delictuales en un plazo de 90 días”, El Mercurio, 12 de octubre de 2015, C 9.

26 Desde ya es necesario recordar que en nuestra actual legislación procesal penal los efectos que tiene una declaración de ilegalidad de una detención son enormemente limitados luego de la reforma introducida al CPP por la Ley $n .^{\circ} 20.253$, de 14 de marzo de 2008. En efecto, ésta no impide la formalización de la investigación en contra del imputado, la solicitud y concesión de medidas cautelares como la prisión preventiva y no produce cosa juzgada en materia de exclusión probatoria por infracción de garantías. Por lo mismo, aun en un escenario en que se decretaran muchas ilegalidades sería dudoso sostener que ellas imponen restricciones fuertes al trabajo policial. Un análisis sobre los efectos de la ilegalidad de la detención en el actual escenario normativo puede verse en Héctor Hernández, "La detención declarada ilegal y sus consecuencias sobre las medidas cautelares y el régimen de exclusión de prueba", en Agenda corta antidelincuencia (Santiago: Centro de Documentación de la Defensoría Penal Pública, 2010), 25. 
lo mismo, es necesario revisar el fundamento empírico de estas afirmaciones para ver si tienen algún sustento.

Más allá del debate lingüístico que se puede tener sobre el alcance del actual artículo 85 del CPP, las cifras del trabajo de Carabineros de Chile ayudan a tener una imagen con soporte empírico y no meramente especulativo acerca de cuán restrictiva o no es en la práctica el uso de esta norma. Según reporta esta institución, durante el año 2014 Carabineros realizó 1.853.244 controles de identidad. ${ }^{27}$ En la tabla 1 se resumen el total de controles de identidad efectuados entre los años 2011 y 2014.

Tabla 1. TOTAL DE CONTROLES DE IDENTIDAD DE CARABINEROS (2011-2014)

\begin{tabular}{|l|l|}
\hline Año & $\mathrm{N}^{\circ}$ controles de identidad \\
\hline 2011 & 2.232 .298 \\
\hline 2012 & 2.361 .161 \\
\hline 2013 & 1.732 .928 \\
\hline 2014 & 1.853 .244 \\
\hline
\end{tabular}

Fuente: Elaboración del autor sobre la base de diversas fuentes. ${ }^{28}$

La magnitud de las cifras parece indicar que estamos muy lejos de contar con una facultad legal de corto alcance, ya que el promedio de su uso en los últimos cuatro años supera los dos millones de controles. Esa cifra podría ser incluso superior si se agregara el monto de los controles realizados por la Policía de Investigaciones, dato que no está disponible.

La importante magnitud de la cifra de controles queda en evidencia cuando se la compara con otros datos de funcionamiento del sistema.

${ }^{27}$ Carabineros de Chile, "Cuenta Pública 2014: Carabineros en cifras", en https:/www.google.cl/webhp?sourceid=chrome-instant\&ion=1\&espv=2\&ie=UTF$8 \# \mathrm{q}=$ carabineros $\% 20 \mathrm{en} \% 20$ cifras. Es importante señalar que estas cifras están desagregadas de los controles vehiculares que se practicaron en el mismo período. Según reporta Carabineros ellos fueron 8.498.620.

${ }^{28}$ Datos del año 2011 obtenidos de Irarrázabal, "Igualdad en Chile”, 242. Datos de los años 2011 y 2012 obtenidos de Instituto Nacional de Derechos Humanos, "Informe anual 2012: programa de derechos humanos y función policial", 37, en http://bibliotecadigital.indh.cl/bitstream/handle/123456789/512/informe-funcionpolicial? sequence $=4$. 
Así, el año 2014, el total de delitos ingresados al sistema de justicia penal fue de 1.348.895, y el total de imputados conocidos llegó a 714.062 personas. ${ }^{29}$ Es decir, los controles de identidad sobrepasan en 37 por ciento el total de los ingresos y en más de 150 por ciento los casos con imputado conocido. En el mismo período Carabineros aprehendió a 432.776 personas, de las cuales 367.138 fueron pasadas a fiscalía. ${ }^{30}$ Es decir, las aprehensiones por figuras delictivas de alguna relevancia penal corresponden a menos del 20 por ciento del total de controles de identidad practicados ese año. Considerando el total de la población nacional al año 2014 - 17.819.054, según el Instituto Nacional de Estadísticas-, los controles de identidad de un año recaerían en más del 10 por ciento de los habitantes. ${ }^{31}$ Como se puede apreciar, el número de controles de identidad da cuenta de una cifra muy importante.

Visto en términos comparados, también es posible apreciar que en Chile hacemos un uso intenso de esta facultad. Nuestra tasa de controles del año 2014 fue de 104 por cada 100 mil habitantes. Se trata de una tasa muy superior a la de países como Inglaterra o Gales, que en el año 2010, contando con facultades similares, realizaron 17 controles por cada 100 mil habitantes; Escocia (año 2010) y la ciudad de Nueva York (año 2012), en tanto, efectuaron 64 controles por cada 100 mil habitantes. $^{32}$

La pregunta natural que surge a partir de estos datos es si efectivamente contamos con una norma restrictiva, que tiene atadas de manos a nuestras policías. Los datos parecen apuntar en una dirección completamente opuesta.

Más allá de la cantidad de controles, parte del argumento que se esgrime por sus propulsores es que la norma actual permitiría un escrutinio intenso de parte de los jueces de garantía, aspecto que sería el verdadero problema de la actual normativa. Nuevamente se trata de un argumento de contenido empírico que requiere ser revisado a la luz de las cifras disponibles del sistema para ver su corrección.

${ }^{29}$ Ministerio Público, "Boletín estadístico institucional año 2014”, en http:// www.fiscaliadechile.cl/Fiscalia/estadisticas/index.do.

${ }^{30}$ Carabineros de Chile, "Cuenta Pública 2014”, 13.

${ }^{31}$ Instituto Nacional de Estadísticas http://www.ine.cl/canales/chile_estadistico/familias/demograficas_vitales.php.

32 Estos datos fueron obtenidos del trabajo de Ben Bradford et al., eds., The SAGE Handbook of Global Policing (London: SAGE, en prensa para 2016). 
Me detengo en el análisis del año 2014 para hacer algunas precisiones sobre esta materia. Una primera cuestión a señalar es que por las cifras disponibles no sabemos cuántos de los 1.853.244 controles de identidad realizados por Carabineros en ese año se tradujeron efectivamente en una detención, hipótesis en la cual se posibilita la revisión judicial de esta facultad en una audiencia (audiencia de control de la detención). ${ }^{33}$ No obstante esto, es de presumir que sólo una porción muy menor del total de controles de identidad se traduce en una judicialización del caso. Piénsese que en el mismo año 2014 Carabineros reporta que 220.545 aprehendidos por ellos pasaron a audiencia de control de detención ante un juez de garantía. ${ }^{34}$ Esta cifra genera el universo máximo de casos potencialmente sujetos a control. Con todo, se trata de una cifra que incluye al universo completo de los detenidos por flagrancia, dentro de los cuales sólo una porción proviene de un control de identidad previo. Por lo mismo, es posible presumir que el escrutinio judicial real del ejercicio de las facultades de control de identidad de las policías es en la práctica muy menor. Esto ya pone serias dudas acerca del argumento que se esgrime para justificar su uso.

Revisemos esto planteando algunos escenarios posibles. En un escenario extraordinariamente deferente para el argumento de quienes sostienen la necesidad de regular el control de identidad preventivo, supongamos que la mitad de las aprehensiones de Carabineros que pasaron a control judicial se explican como consecuencia de controles de identidad de conformidad al actual artículo 85 del CPP. En este escenario, eso significaría que sólo cerca del 6 por ciento del total de controles de identidad podría potencialmente ser objeto de control judicial. En un escenario más limitado y que, estimo, se acerca más a la realidad, suponiendo que el 25 por ciento de las aprehensiones de Carabineros

${ }^{33} \mathrm{Si}$ el control de identidad no se traduce en una detención (ya sea por flagrancia o por existencia de una orden de detención pendiente de la persona controlada), el caso no será objeto de revisión judicial. En efecto, sólo los casos que generan una detención son llevados ante un juez de garantía dentro de las 24 horas siguientes a esa privación de libertad. Esto, salvo casos excepcionalísimos en donde el controlado, a pesar de ser puesto en libertad rápidamente sin ser pasado a una audiencia, ejerce alguna acción especial, por ejemplo, el recurso de amparo establecido en el artículo 21 de la Constitución. Un caso en donde esta situación se produjo puede verse en Vidal con Carabineros, Corte de Apelaciones de Santiago, 19 de julio de 2012, ROL n. ${ }^{\circ} 1393-2012$.

${ }^{34}$ Carabineros de Chile, “Cuenta Pública 2014”, 13. 
que pasaron a control judicial se originaron en el artículo 85 del CPP, ello supondría que sólo alrededor del 3 por ciento de los controles de identidad es objeto de control judicial. Como se puede observar, en cualquiera de los dos escenarios, el porcentaje de controles de identidad sujetos a revisión judicial es extremadamente bajo y hace poco probable el argumento de que el trabajo de los jueces esté impidiendo a las policías ejercer esta facultad con intensidad.

Ahora bien, esto es sólo una parte del argumento. También es relevante estudiar qué pasa con los controles judiciales a esas detenciones, ya que la razón que se esgrime para justificar esta nueva facultad se construye invocando que en sede judicial se realiza un escrutinio muy estricto al trabajo policial. Por lo mismo, aun cuando fueran pocos los casos objeto de revisión judicial, lo relevante sería la señal que esos controles envían a las policías, la que aparentemente sería muy restrictiva. La señal entonces podría ser un dato más relevante que la cantidad de controles.

Sin embargo, los datos disponibles nuevamente muestran más bien lo contrario. Las cifras que proporciona el Poder Judicial para el año 2014 dan cuenta de que sólo el 0,77 por ciento de las detenciones que fueron objeto de control judicial fueron declaradas ilegales. ${ }^{35}$ Se trata de una información no desagregada, que impide conocer si el problema de esas ilegalidades estuvo en los controles de identidad o en otras razones. En todo caso, el punto que se puede destacar es que se trata de un porcentaje bajo de ilegalidades, que tiende a mostrar que los procedimientos policiales son validados regularmente en sede judicial.

Para efectos de dar una imagen, si suponemos que las ilegalidades se distribuyen equitativamente en las detenciones de acuerdo a sus distintos orígenes, en el escenario más favorable que analicé previamente (50 por ciento de las aprehensiones originadas en control de identidad), esto significaría que sólo el 0,065 por ciento de los controles de identi-

${ }^{35}$ Se trata de 2.413 detenciones ilegales de un total de 311.960 detenciones controladas en audiencia. Cifras del Poder Judicial en http:/www.pjud.cl/documents/396729/0/UN+RELATO+EN+CIFRAS.pdf/71ba680e-1e4b-4d8d-90fd1e71cf52a8d5. En la misma dirección, los datos de la Defensoría Penal Pública dan cuenta de que en el año 2014 sólo el 1,4 por ciento de las detenciones fueron declaradas ilegales por los jueces de garantía. Defensoría Penal Pública, "Informe Estadístico enero-diciembre 2014", 55, en http:/www.dpp.cl/resources/upload/files/ documento/555763f4bd21e53f40323cab2cee5dfc.pdf. 
dad generarían una declaración de ilegalidad. Si hacemos este ejercicio en el escenario de 25 por ciento la cifra bajaría al 0,032 por ciento de los controles. ${ }^{36}$

En consecuencia, las cifras disponibles del sistema dan cuenta de que la gran mayoría de los controles de identidad no son objeto de control judicial y que, cuando lo son, un porcentaje muy bajo es considerado ilegal. Esto refuerza entonces el punto de vista de que los diagnósticos que fundamentan la propuesta de reforma no se condicen con la realidad de funcionamiento del sistema $\mathrm{y}$, por lo mismo, podrían no ser útiles para resolver los problemas de fondo que hoy preocupan a la ciudadanía y que supuestamente justifican la existencia de esta propuesta.

Junto con lo anterior, también es posible ver este mismo tema desde una perspectiva más cualitativa, es decir, considerando cómo ha sido interpretada esta facultad en la práctica por nuestros tribunales. Se podría sostener que, independiente de las cifras, las señales que envían los tribunales a las policías podrían generar la sensación de que este tipo de facultad se debiera utilizar en forma muy restrictiva. Sobre este punto, lo primero que se debe recordar es que la redacción actual del artículo 85 del CPP es producto de reformas sucesivas que intentaron precisamente aclarar y perfeccionar el sentido y alcance de la regla. La actual redacción se encuentra consolidada desde el año 2008. A más de siete años de su última reforma, los problemas potenciales de interpretación que presentaba esta figura han ido siendo resueltos por una enorme cantidad de jurisprudencia de nuestros tribunales superiores en la materia, incluida la propia Corte Suprema. Me parece posible afirmar que esta jurisprudencia presenta una clara tendencia a interpretar flexiblemente los requisitos del artículo 85 del CPP y conferirles bastantes espacios de discrecionalidad a las policías para evaluarlos. ${ }^{37}$ Así se ha ido con-

${ }^{36}$ Considerando las cifras de la Defensoría Penal Pública, esos porcentajes se elevarían al 0,08 en el escenario del 50 por ciento y al 0,04 en el escenario del 25 por ciento.

${ }^{37}$ A modo ejemplar, pueden verse sentencias Toledo con Sáez, Corte de Apelaciones de San Miguel, 5 de julio de 2010, ROL n. ${ }^{\circ}$ 819-2010; García con Juzgado de Garantía de Los Ángeles, Corte de Apelaciones de Concepción, 29 de julio de 2010, ROL n. ${ }^{\circ}$ 356-2010; Ormeño Durán y otro con Juzgado de Garantía de Arauco, Corte de Apelaciones de Concepción, 10 de junio de 2011, ROL n. ${ }^{\circ} 226-2011$; y, Rojas con Ministerio Público, Corte Suprema, 27 de septiembre de 2010, ROL n. ${ }^{\circ}$ 4600-2010. 
solidando una doctrina jurisprudencial que establece que Carabineros puede realizar controles de "rutina"; que el hecho de que una persona se ponga nerviosa o que se encuentre en un lugar y hora inapropiado es un indicio que habilita a la práctica del control de identidad, entre otras. ${ }^{38}$ Por lo mismo, si se consideran estas señales tampoco pareciera haber mucho sustento para el argumento que se ha dado.

En definitiva, el análisis de los datos da cuenta de que el control de identidad previsto en el actual artículo 85 del CPP es utilizado ampliamente por Carabineros sin control intenso de parte de los tribunales. También nos muestra que cuando se ejerce dicho control, los jueces muy mayoritariamente validan su legalidad. Finalmente, la jurisprudencia de tribunales superiores da cuenta de que se ha interpretado esta facultad de una manera bastante favorable a su uso por parte de los cuerpos policiales. Esto contradice de manera clara los argumentos esgrimidos por los propulsores de este cambio y da cuenta de dos cosas posibles: desconocimiento de la realidad a la hora de promover reformas legales o, peor aún, el que este debate ha sido llevado adelante utilizando argumentos a sabiendas de su incorrección empírica.

\section{3. ¿El control de identidad preventivo sería una carga menor a los derechos ciudadanos?}

Otro argumento para justificar esta facultad es que la regulación del control de identidad preventivo propuesto no sería muy problemática, ya que impone una "carga menor" a los ciudadanos. Esta carga estaría constituida por tolerar la realización de procedimientos muy breves y poco intrusivos, como exhibir un documento público de identificación. En este sentido, incluso se compara los controles de identidad con los controles vehiculares que realiza la policía. ${ }^{39}$

Esta línea de justificación parece razonable a primera vista, sin embargo, no refleja los alcances reales de la facultad que se pretende regular. Desde el punto de vista de su diseño normativo, el control de identidad preventivo no sólo entrega facultades a las policías para exigir

${ }^{38}$ Apoyando estas conclusiones con cita de diversos fallos de Cortes de Apelaciones y Corte Suprema no incluidos en la referencia anterior, puede verse Irarrázabal, "Igualdad en Chile", 245-246.

${ }^{39}$ Pavez, "Control". 
identificación a una persona sin ninguna justificación previa, sino que además — como ya he mencionado — abre la posibilidad de que las personas controladas sean "retenidas" hasta por cuatro horas en un cuartel para efectos de identificarse, sin revisión judicial, ya que la mayoría de esos controles no generan un procedimiento de ese tipo como he señalado. Más allá del nombre que eufemísticamente se le asigne a este procedimiento policial, se está en presencia de una detención de corto tiempo, lo que afecta de manera significativa el derecho a la libertad personal y a la libre circulación.

No estamos en presencia entonces de una "carga menor", sino que de una potencial privación de un derecho fundamental. En este sentido, quienes sostienen que el que "nada hace nada debe temer" no consideran que el problema de esta propuesta es que quien nada hace y nada teme puede ser privado de libertad hasta por varias horas, precisamente, por no haber temido nada y olvidar su documento de identificación en su casa u oficina el día en que por "mala suerte" se le práctica un control de identidad preventivo. Es en este contexto que se explica que cinco ministros de la Corte Suprema, en el informe preparado por la Corte al proyecto de ley, quisieran dejar expresa constancia que en su opinión las reformas propuestas en materia de control de identidad eran “...difícilmente aceptable[s] desde la perspectiva de un estado democrático de Derecho". ${ }^{40}$

En un nivel diferente de análisis, los argumentos de los propulsores de este cambio no se hacen cargo de cómo opera en la práctica el uso de esta facultad. Evidencia disponible da cuenta de que en la operación cotidiana del sistema las policías, especialmente Carabineros, "retienen" con cierta frecuencia a la persona objeto de control en sus vehículos policiales o la trasladan al cuartel que corresponda, no obstante ella pueda contar con su documento de identificación disponible en ese momento. De esta manera, las personas controladas sufren privaciones de libertad de algunas horas a pesar de que podían ser identificadas en el momento mismo que se practicó el control. Carabineros trata a estas personas como "conducidas" y no detenidas. ${ }^{41}$ Esta práctica genera, a su vez, un

${ }^{40}$ Corte Suprema, "Oficio n. ${ }^{\circ} 102-2015 ", 14$ de septiembre de 2015, 9 (documento electrónico en poder del autor).

${ }^{41}$ El Instituto Nacional de Derechos Humanos ha documentado estas prácticas y las describe en sus informes sobre el uso de esta facultad. Instituto Nacional de Derechos Humanos, "Informe anual 2012", 35-36. En la misma dirección también se pronuncia Irarrázabal, "Igualdad en Chile", 242-243. 
espacio para situaciones conflictivas en las que se han generado problemas de abuso policial graves en diversos casos. ${ }^{42}$

Finalmente, otro problema de diseño normativo, que da cuenta de la tensión que genera la institución propuesta con los derechos fundamentales de los ciudadanos, tiene que ver con la poca claridad en la norma del proyecto respecto a las facultades adicionales intrusivas que otorgaría a las policías, tales como la revisión de vestimentas, equipajes y vehículos de la persona controlada. Si bien, como ya señalaba, la norma propuesta no se pronuncia sobre este punto, resulta bastante obvio que al menos la revisión de vestimentas se justificará por motivos de seguridad de los propios funcionarios controladores. Sería muy problemático que una norma entregue facultades policiales de retención y traslado de una persona y no entregue, a la vez, facultades de revisión que le permitan al funcionario a cargo del procedimiento evitar riesgos a su integridad física, verificando si la persona porta o tiene acceso a algún tipo de arma con la que podría intentar atacarlo durante el desarrollo del mismo. En consecuencia, es posible proyectar que, a pesar del silencio que sobre el punto tiene la regla propuesta, la gran mayoría de los controles llevarán asociados registros de diverso tipo sobre las personas objeto de los mismos.

\section{4. ¿Se trata de una facultad ampliamente reconocida en el derecho comparado?}

Quienes proponen esta reforma invocan insistentemente, como apoyo a su punto de vista, que se trataría de una facultad reconocida en diversas legislaciones comparadas. En esta línea, se pretende argumentar que las facultades de controlar preventivamente la identidad no entrarían en pugna relevante con los derechos ciudadanos, ya que países con mucha tradición democrática y altos estándares de protección de

42 En este sentido, Rodrigo Bustos, jefe de la unidad Jurídica del Instituto Nacional de Derechos Humanos, ha sostenido recientemente, en una entrevista sobre actos de tortura y abuso policial que hoy se encuentran en investigación, lo siguiente: "Es importante aclarar que estos actos de tortura se dan en el marco de un control de identidad, y eso es clave en el debate actual donde algunos buscan darle más facultades a la policía". "Torturas en democracia: los casos que denuncian la brutalidad de Carabineros contra civiles", El Mostrador, 6 de agosto de 2015. 
derechos individuales recurren a ellas. El problema de este argumento es que muchas de las referencias al derecho comparado que se realizan por quienes defienden la propuesta son erróneas. Una revisión cuidadosa de las legislaciones que se invocan permite concluir que lo que en ese ámbito se regula es más bien la facultad que hoy día el actual artículo 85 del CPP ya les confiere a las policías. Visto desde el lado opuesto, una facultad como la que se propone en el artículo 12 del proyecto de ley aprobado por la Cámara de Diputados no existe.

La riqueza del derecho comparado en esta materia es enorme y un análisis sistemático del mismo excedería los alcances de un artículo como éste. Afortunadamente, una parte importante de este trabajo ya ha sido realizado por la biblioteca del Congreso a propósito del trámite legislativo de este proyecto en la Cámara de Diputados, y eso me libera de una carga argumentativa superior en la materia. El informe preparado por la biblioteca del Congreso fue presentado a la sesión 119, del 11 de agosto de 2015, de la Comisión de Constitución, Legislación, Justicia y Reglamento de la Cámara de Diputados. Dicho informe, luego de revisar las normas de países como Alemania, Estados Unidos, España y Francia, concluye que “...ninguna de las normas estudiadas permite controlar la identidad de cualquier persona sin causa justificada". ${ }^{43}$

Sin poder hacer el análisis de todas estas legislaciones, recojo sólo un par de ejemplos de países para mostrar con más precisión la forma equivocada en que ha sido utilizado el derecho comparado en el debate legislativo. Así, dos casos que se citaron con fuerza durante la tramitación en la Cámara de Diputados fueron el derecho de Alemania y el de los Estados Unidos. Sin embargo, en tales países facultades policiales de este tipo operan en la lógica de que un supuesto básico para la autorización del control está en la existencia de una sospecha basada en algún hecho objetivo. Esto es exactamente la hipótesis del control de identidad en nuestra legislación procesal penal del actual artículo 85 del CPP. Veamos con un poco más de detalle ambos ejemplos.

Parto con la revisión de la legislación alemana nacional. El parágrafo 163 b) de la Ordenanza Procesal Penal Alemana contempla dos hipótesis

${ }^{43}$ Biblioteca del Congreso Nacional, "Control de identidad en la legislación comparada", 11 de agosto de 2015, 1, en http://www.camara.cl/pdf.aspx?prmID=36 052\&prmTIPO=DOCUMENTOCOMISION. 
para practicar controles de identidad. En la primera se exige explícitamente para autorizar el control de identidad el que la persona "sea sospechosa de un hecho punible", habiéndose entendido en dicho país que para poder utilizar esta norma siempre es requerida la existencia de hechos concretos que permitan fundar la creencia de que el controlado es autor de un delito específico. ${ }^{44}$ En la segunda, se admite el control de identidad de un no sospechoso cuando ello sea necesario para el esclarecimiento de un hecho punible, ${ }^{45}$ para lo cual, sostiene Casal Hernández:

...es preciso que en el momento de ser practicada esa medida exista la creencia fundada de que el conocimiento de la identidad del afectado, por el testimonio que pueda prestar o por hallarse en su cuerpo huellas del delito o consecuencias del mismo, contribuirá al desarrollo de la investigación penal. ${ }^{46}$

En consecuencia, en ambas hipótesis se requieren elementos de sospecha relevantes para permitir la intervención policial.

A nivel de legislación estadual alemana, se ha citado en la tramitación legislativa específicamente la regulación del Land de Hessen. El artículo 18 de la ordenanza respectiva ("Hessisches Gesetz über die öffentliche Sicherheit und Ordnung") autoriza un control de identidad cuando la policía pretende "evitar un peligro, ante la sospecha que permita creer que se comete o se cometerá un delito". ${ }^{47}$ Como se puede ob-

44 Jesús María Casal Hernández, Derecho a la libertad personal y diligencias policiales de identificación (Madrid: Centro de Estudios Políticos y Constitucionales, 1998), 190. Este texto también es citado en Chile por César Ramos y María Merino, "Control de identidad", Memoria para la obtención del grado de licenciado en ciencias jurídicas y sociales (Santiago: Universidad de Chile, 2010), 26.

${ }^{45}$ Roxin señala que en esta segunda hipótesis la opinión dominante en Alemania ha concluido que "...el registro de su persona y de las cosas que lleva consigo, así como las medidas tendientes a su identificación, sólo están permitidas con su conformidad... de donde concluye que se debe pedir su consentimiento positivo y no sólo apoyarse en la inexistencia de una oposición declarada expresamente o reconocible". Claus Roxin, Derecho procesal penal (Buenos Aires: Editores del Puerto, 2003), 284.

46 Casal Hernández, Derecho, 191.

47 Defensoría Nacional, "Observaciones al proyecto de ley que facilita la aplicación efectiva de las penas establecidas para los delitos de robo, hurto y receptación y mejora la persecución penal en dichos delitos (Boletín n. $\left.{ }^{\circ} 9885-07\right)$ ", julio $2015,23$. 
servar, nuevamente se está en presencia de una regla que supone como mínimo la existencia de una sospecha para fundar la intervención de la policía, todo ello en una lógica muy similar a la de la regla actual contenida en el artículo 85 del CPP.

Algo similar ocurre en los Estados Unidos. Allí la facultad policial en análisis es conocida como "stop and frisk". Ella permite a la policía controlar a una persona y realizar una revisión superficial de sus vestimentas (por motivos de seguridad) sólo cuando el policía "observa una conducta inusual que le permite generar una sospecha razonable en base a su experiencia que una actividad criminal puede estarse llevando a efecto". ${ }^{48} \mathrm{El}$ foco de la facultad policial se encuentra en la existencia de una sospecha, la cual se estima debe ser menor al de "probable cause" (causa probable) exigida para arrestar a una persona, pero de todas maneras basarse en hechos que permitan razonablemente generar una sospecha. ${ }^{49}$ Esta doctrina se mantiene vigente al día de hoy, existiendo diversos casos en los que la Corte Suprema ha precisado los alcances de la "sospecha razonable" para autorizar el uso de esta facultad. ${ }^{50}$ Junto con autorizarse el control policial ("stop"), la jurisprudencia posterior de la Corte Suprema de los Estados Unidos ha precisado que si hay sospecha razonable es posible realizar medidas intrusivas sobre la persona controlada, pero limitadas al foco relacionado con la causa que justificó el control. Dentro de ellas, la solicitud de identificación. ${ }^{51}$

48 Se trata de una facultad reconocida jurisprudencialmente por la Corte Suprema de los Estados Unidos a partir del caso Terry v. Ohio, 392 U.S. 1 (1968). Detalles en Joshua Dressler, Understanding Criminal Procedure (New York: Mathew Bender, 1998), 255-278.

${ }^{49}$ Una breve explicación en castellano de la misma puede verse en Rabi, "Qué rol", 343-349.

${ }^{50}$ Por ejemplo, se ha establecido que la sola "corazonada" (hunch) del policía no es suficiente para crear sospecha razonable, pero un dato anónimo de un denunciante rodeado de suficientes detalles corroborados por los policías sí podría serlo. Uno de los fallos más recientes en la materia donde se realiza un análisis de este punto es Prado Navarrete et al. v. California, 572 U.S.__ (2014).

51 Hiibel v. Sixth Judicial District Court of Nevada, 542 U.S. 3 (2004). Analizando el desarrollo de esta jurisprudencia con foco en el caso Hiibel: Peter Koclanes, "Unreasonable Seizure: 'Stop and Identity' Statutes Create an Illusion of Safety By Sacrificing Real Privacy”, Florida Law Review 57 (2005): 431. 
Facultades similares se han regulado en legislaciones de varios estados en leyes conocidas como "Stop and Identity". A enero de 2012, 24 estados contaban con regulaciones en esta materia. ${ }^{52}$ Un análisis realizado por la Corte Suprema de los Estados Unidos en el caso Hiibel -año 2004 - da cuenta de que estas regulaciones consideran como un supuesto básico que autoriza a la policía a detener y solicitar identificación de una persona algún tipo de sospecha basada en los hechos del caso. ${ }^{53}$

Como se puede apreciar en esta somera revisión ejemplar, la legislación comparada citada regula algo distinto a lo que se pretende con el control de identidad preventivo. Esta propuesta pretende autorizar la facultad de control sin sospecha de ningún tipo y sin restricciones ni temporales ni espaciales (como por ejemplo la regla del artículo 21 de la Ley n. ${ }^{\circ}$ 19.327). Creo que el lector está en condiciones de concluir que esto va mucho más allá de lo admitido en el ámbito comparado. Es importante destacar que aun cuando se considere bueno o loable el fin perseguido por este proyecto, ello no constituye un parámetro suficiente para justificar este tipo de intervención. Esto, ya que, entre otras cosas, admitir una regla de este tipo suprime cualquier posibilidad de control racional de su uso debido a la inexistencia de un supuesto mínimo para autorizar su procedencia. Si se trata de una facultad completamente discrecional de las policías, eso impide en la práctica un control de legalidad de su procedencia.

Otro caso de mal uso del derecho comparado para justificar la propuesta se verifica cuando se citan normas que establecen cosas diversas a las que se pretende regular con el proyecto. Sólo como ejemplo, menciono la referencia que se hace al artículo 651 del Código Penal italiano, que se describe como una regulación equivalente a lo que se pretende hacer con el control de identidad preventivo. ${ }^{54}$ Pero dicha norma regula algo completamente distinto. Ella se hace cargo de regular el régimen de infracción al deber de identificarse y no de establecer cuáles son las facultades policiales para requerir dicha identificación, lo que es precisamente objeto de regulación en el artículo 12 propuesto. Se puede

52 Biblioteca del Congreso Nacional, "Control", 8.

${ }^{53}$ Hiibel v. Sixth Judicial District Court of Nevada, 542 U.S. 3 (2004). Un análisis detallado de esta decision en Shelli Calland, "Hiibel v. Sixth Judicial District Court: Stop and Identity Statutes Do Not Violate the Fourth or Fifth Amendments", Harvard Civil Rights - Civil Liberties Law Review 40 (2005): 251.

${ }^{54}$ Véase Nogueira, "Control" (25 de mayo). 
apreciar que hay un error al interpretar la regla. Una cosa es establecer deberes de identificación y otra, muy distinta, es regular los casos en que la policía está autorizada para exigir esa información. ${ }^{55}$ De hecho, sobre el primer punto (el deber de identificarse), la norma italiana citada encuentra un equivalente funcional en nuestro artículo 496 n. 5 del Código Penal vigente y que es utilizado en la práctica con cierta regularidad según muestran los datos disponibles. ${ }^{56}$

Como se puede apreciar, el derecho comparado no permite sustentar una propuesta como la que se pretende introducir por vía del control preventivo de identidad. En una dirección contraria, más bien refuerza que el artículo 85 actual del CPP parece ser el tipo de herramienta que se concede a la policía para el cumplimiento de sus funciones. Nuevamente queda en duda la forma en que hemos estado legislando en la materia. Afortunadamente el informe de la biblioteca del Congreso citado pone cierre al uso de esta línea argumental, que se repitió durante meses en el debate público.

\section{5. ¿El control de identidad preventivo puede impactar positivamente en materia de seguridad ciudadana y delincuencia?}

He dejado para el final el punto vinculado a la eficacia potencial que podría tener esta facultad. Los partidarios de regularla sostienen que ella es indispensable para poner término a las órdenes de detención pendientes y que, además, podría tener un impacto relevante en la prevención y disminución de los índices de criminalidad. No obstante, pese a las buenas intenciones que existen detrás de estas ideas, ellas no pasan

${ }^{55}$ El caso Hiibel de la Corte Suprema de los Estados Unidos ya citado previamente analiza este punto, dando cuenta que se trata de dos cuestiones diversas. Una vez resuelto que la policía contaba con sospechas razonables de que la persona a quien se controló y luego solicitó identificación estaba involucrada en un hecho delictual (supuesto base para el stop and identity), la Corte considera necesario revisar la constitucionalidad de reglas que sancionan al controlado por negarse a exhibir su identidad. La Corte Suprema afirma que dicha regla en el caso particular era constitucional y no violaba ni la cuarta ni la quinta enmienda.

56 Datos disponibles del año 2013 dan cuenta de que en ese período 1.142 personas fueron arrestadas por Carabineros como consecuencia de una negativa a identificarse. Dato obtenido a través de una solicitud de acceso de información consignado por Irarrázabal, "Igualdad en Chile", 242. 
de ser un deseo voluntarista sin fundamento empírico ni justificación clara. $^{57}$

Lidiar efectivamente con la delincuencia supone tener mucha información sobre cuestiones básicas que no parecen estar sobre la mesa en el debate actual. En esta dirección, ¿qué problema delictual concreto podría resolver esta facultad? ¿Qué efectivamente podrían hacer las policías que hoy no hacen? ¿Cómo esta facultad permitiría desbaratar bandas criminales que han aumentado su sofisticación y violencia? Se trata de preguntas que no tienen respuestas mínimas de parte de quienes sostienen la necesidad de establecer los controles de identidad preventivos. Incluso, esta falta de respuestas existe en preguntas más básicas que constituyen el supuesto sobre el cual se propone este cambio legal. Por ejemplo, ¿sabemos de qué se tratan las más de 66 mil órdenes de aprehensión vigentes? ¿Por qué esas órdenes no se ejecutan si es que las policías tienen amplias facultades legales para ello? Como el lector podrá apreciar, sin información como ésta, la posibilidad de que una propuesta legal de esta naturaleza cambie la realidad es muy baja.

Es por eso que especialistas en la materia sostienen que la regulación de algún tipo de control de identidad (no necesariamente el que se propone) sólo cumpliría un rol "complementario a la gestión que se hace en el territorio entre policías y fiscales". ${ }^{58}$ Incluso más, se ha sostenido sobre la base de análisis de las cifras del sistema que ni siquiera esta facultad atacaría los problemas que en la práctica éste presenta. Así, Jean Pierre Matus ha sostenido que:

...como indican las cifras antes expuestas el problema principal de nuestro sistema de justicia criminal no es la falta detenciones por parte de la policía en casos de flagrancia, sino lo que se hace

57 En esta dirección, Pía Greene, ex asesora del Ministerio del Interior y Seguridad Pública, hace un llamado a descansar más en evidencia que en intuición en materia de delincuencia. Así, señala: "La evidencia es categórica al demostrar que si se quiere atacar decisivamente la delincuencia y mantener los resultados, es clave implementar políticas que hayan demostrado su éxito y sean evaluables en su impacto". Pía Greene, "Más evidencia menos intuición", La Tercera, 28 de julio de 2015.

${ }^{58}$ Afirmaciones de Catalina Mertz, directora de la Fundación Paz Ciudadana, a EMOL. "Paz Ciudadana refuta al Gobierno por delincuencia: 'Si no hubiese delitos no habría sensación de temor'”, EMOL, 28 de julio de 2015. 
con los detenidos una vez que son puestos a disposición de fiscales y jueces. ${ }^{59}$

Todo lo cual le permite concluir que el impacto de una norma de control de identidad preventivo en materia de los problemas de delincuencia debiera ser muy bajo o nulo. Mauricio Valdivia, teniente coronel en retiro de Carabineros y doctor en psicología criminal, ha sostenido sobre el punto que "la evidencia empírica es clara: aumentar las facultades policiales, como hace el control de identidad preventivo, no mejora la prevención (es decir, no reduce la criminalidad)..." ${ }^{60} \mathrm{Su}$ impacto, asegura, está más bien en empoderar a la policía, el que parece ser un objetivo bastante distinto. Maina Kiai, relator especial de Naciones Unidas sobre los derechos a la libertad de reunión pacífica y de asociación, realizó una visita a Chile en el mes de septiembre de 2015 y estudió esta materia. En su informe de conclusión de su visita, dado a conocer el 30 de septiembre de 2015, en referencia al artículo 12 aprobado por la Cámara de Diputados, señaló:

....no estoy convencido que la ley sería eficaz en combatir la delincuencia. De hecho, podría hacer lo contrario: permitir a la policía detener aleatoriamente a cualquier persona que escoja sin evidencia alguna o sospecha clara es una vía que promueve una custodia poco eficaz y contraproducente. Las fuerzas policiales eficaces pueden realizar sus funciones sin interferir con los derechos fundamentales. Confío en que Carabineros de Chile es eficaz y que no necesita - y no se beneficiaría con — tales atajos. ${ }^{61}$

Este tipo de consideraciones ha hecho que diversos medios de comunicación escritos hayan planteado en sus editoriales dudas importantes respecto a la capacidad del control de identidad preventivo para

59 Jean Pierre Matus, "Control de identidad, sistema acusatorio y Estado de Derecho", El Mercurio Legal, 9 de octubre de 2015.

${ }^{60}$ Mauricio Valdivia, "Objetivo del control de identidad", La Tercera, 12 de septiembre de 2015, sección cartas.

61 "Comunicado de Maina Kiai, relator especial de las Naciones Unidas sobre los derechos a la libertad de reunión pacífica y de asociación, al término de su visita a la República de Chile (21 al 30 de septiembre de 2015)", en http://www.ohchr.org/ SP/NewsEvents/Pages/DisplayNews.aspx?NewsID=16542\&LangID=S. 
contribuir razonablemente con los objetivos de la seguridad ciudadana. ${ }^{62}$ Adoptando una posición muy crítica, un editorial de La Segunda sostuvo: "No existe evidencia empírica de que ampliar la facultad de control disminuya el delito. El riesgo es que terminemos de creer que sí funciona o, como lo advertía Baudrillard, que el simulacro se vuelva verdadero". 63

En este escenario de serias dudas respecto a la posibilidad real de esta facultad de cumplir con el objetivo propuesto, resulta interesante nuevamente recurrir a la cuenta realizada por el general de Carabineros Gonzalo Blu respecto a las metas anti delincuencia establecidas en julio de 2015 por la institución. Ella, me parece, es muy esclarecedora acerca de la real necesidad de este cambio para aportar con el principal problema de seguridad ciudadana que han invocado sus propulsores: la vigencia de más de 66 mil órdenes de detención pendientes. En esta cuenta se señala que en dos meses de establecidas las nuevas metas fueron capturadas cerca de 19 mil personas con órdenes de detención pendientes. Esto fue logrado sin necesidad de ninguna reforma legal, sino simplemente gracias a un cambio de estrategia policial. Es decir, modificando la forma de trabajo y poniendo foco en el problema de reducir las órdenes de detención pendientes, en dos meses Carabineros fue capaz de reducir de manera significativa el problema central que justificaría esta propuesta. Como se puede apreciar, estos hechos parecen ratificar fuertemente las opiniones de los expertos y medios de comunicación citados previamente.

62 Un buen ejemplo lo constituye un editorial de El Mercurio del 7 de septiembre de 2015, en donde se explicitó los enormes límites del proyecto llamando a la cautela respecto a su capacidad para generar verdadero impacto en materia de seguridad ciudadana y poniendo, a la vez, la atención sobre sus potenciales consecuencias para los derechos individuales de las personas. En ella se señaló: "Por cierto que la prevención del delito requiere mucho más que una nueva regla sobre control de identidad. En especial, es indispensable una mayor profesionalización y coordinación de todas las instituciones y servicios asociados a la prevención y persecución del delito con resultados tangibles que hoy no se ven. Pero la nueva atribución pondrá en manos de las policías un instrumento importante y debatido, que ellas mismas han solicitado. La ley que lo establezca obligará a los ciudadanos a ceder una porción de su privacidad - y, en ocasiones, también de su libertad ambulatoria - en aras de obtener efectivamente una mejor seguridad pública. Por esta razón, el Estado y las policías deben ser particularmente conscientes de que el sacrificio en materia de libertades sólo estará justificado en la medida en que se observen frutos concretos en la prevención del delito. Sin estos resultados, la regla sólo dará lugar a un Estado con menos libertades que antes". "Control de identidad", El Mercurio, 7 de septiembre de 2015, A3, en http://www.elmercurio.com/ blogs/2015/09/07/35030/Control-de-identidad.aspx.

63 “Otro control innecesario", La Segunda, 4 de septiembre de 2015. 


\section{LOS RIESGOS Y PROBLEMAS POSIBLES AL INTRODUCIR UN CONTROL DE IDENTIDAD PREVENTIVO EN CHILE}

A esta altura espero haber demostrado la poca calidad del debate en torno a las justificaciones esgrimidas por los propulsores de establecer un control preventivo de identidad en nuestro país. Ello debiera ser suficiente para poner en duda la necesidad de avanzar con esta legislación. Con todo, no se trata del único problema que ha enfrentado el debate legislativo en la materia. La introducción de una facultad de este tipo genera riesgos y problemas importantes. Es necesario revisarlos, aun cuando sea en forma breve, ya que los propulsores de esta reforma no se han hecho cargo de ellos y, en cambio, han sostenido que la aprobación del control de identidad preventivo sólo produciría ventajas.

Los riesgos pueden identificarse en dos ámbitos. Por una parte, se presentan a nivel de vigencia de derechos y libertades públicas. Por la otra, surgen en relación con la conveniencia del cambio para el mejoramiento del trabajo policial. En lo que sigue, reviso ambas dimensiones.

\subsection{Riesgos y problemas para el ejercicio de derechos y libertades públicas}

Como he señalado, un problema importante al regular el control de identidad preventivo es que, en el uso, estas facultades se ejercerían con un control mínimo, lo que abre enormes espacios para privaciones o restricciones arbitrarias a la libertad ambulatoria y para el desarrollo de abusos de distinto tipo. En la práctica, el escaso control judicial que hoy permite el artículo 85 del CPP desaparecería, ya que la regla propuesta derogaría al actual control de identidad. En efecto, si el control de identidad preventivo entrega facultades de intervención a las policías muy similares a las del artículo 85 del CPP pero sin sus exigencias, no se ve en la práctica ninguna razón para preferir el uso de esta regla. ${ }^{64}$

${ }^{64}$ En el debate sostenido en la Comisión de Seguridad Ciudadana, el diputado Soto, presidente de la misma, hace notar esta situación. Comisión de Seguridad Ciudadana Cámara de Diputados, “Acta sesión $41^{\mathrm{a}}$ ordinaria correspondiente a la $363^{a}$ legislatura”, 6 de mayo de 2015, 6. La Defensoría Penal Pública también se pronuncia en la misma dirección. Defensoría Nacional, “Observaciones”, 22. 
Los partidarios de este control preventivo sostienen que este escenario no es esperable, ya que el mal uso de las mismas podría dar lugar a sanciones administrativas y penales. Si bien en teoría dicha responsabilidad podría existir, la práctica actual da cuenta de que no se trata de un límite efectivo o idóneo. Lo cierto es que en la actualidad el artículo 85 del CPP también contempla la posibilidad de imponer sanciones penales sin que ello en la práctica haya ocurrido. Las razones de esto son múltiples. Por una parte, existen barreras y obstáculos de diverso tipo que dificultan la denuncia de prácticas abusivas por parte de ciudadanos comunes y corrientes. ${ }^{65}$ Pero, además, las sanciones penales o administrativas representan formas de control ex post, con estándares normalmente elevados, de difícil aplicación por la gravedad de las consecuencias que ellas implican para los funcionarios sancionados. ${ }^{66}$

En este contexto, la amplitud de las facultades que confiere la regla propuesta a las policías, sumada a la inexistencia en la práctica de controles para su uso, permite afirmar que estamos frente a una facultad inédita en el ámbito comparado y riesgosa para los derechos individuales. Maina Kiai, el relator especial de la ONU ya citado, se pronunció en su informe en esta misma dirección. Allí señala que “...la entrega de mayores facultades y discrecionalidad a las fuerzas del orden generará oportunidades para la represión y abuso de autoridad, con poco o ningún control y contrapeso". ${ }^{67}$

Especialmente debemos considerar que no todos los chilenos somos "potenciales objeto" de control de identidad, sino que éste se

${ }^{65}$ En esta dirección Irarrázabal señala que la existencia ocasional de denuncias por abuso en el ejercicio del control de identidad es explicada por la carencia de sustento necesario o incentivos de los ciudadanos afectados para cuestionar la actividad policial y por la insuficiencia de los canales institucionales utilizados en la actualidad. Con mayor extensión en este punto véase Irarrázabal, "Igualdad en Chile", 243-245.

${ }^{66}$ Irarrázabal se muestra escéptica de la posibilidad real de establecer responsabilidad de los funcionarios policiales por estos mismos motivos. Así, señala: "Habrá, por ejemplo, dificultades probablemente insuperables para determinar que el carabinero actuó guiado por prejuicios y estereotipos (discriminación directa) y, más difícil aún, demostrar el impacto desproporcionado que el funcionamiento del poder policial tiene respecto de los grupos más vulnerables (discriminación indirecta)." Paz Irarrázabal, "Controles preventivos y la amenaza para la igualdad", El Mostrador, 18 de septiembre de 2015.

67 "Comunicado de Maina Kiai". 
focaliza en personas jóvenes ${ }^{68}$ y que pertenecen a ciertos grupos sociales, lo que hace que la proporción entre el total de controles y número de ciudadanos potencialmente controlables sea aún mayor en el grupo objetivo donde normalmente se ejercen. ${ }^{69}$ La escasa evidencia empírica disponible en Chile indica que en la actualidad el control de identidad del artículo 85 del CPP presenta cuestionamientos de diversos grupos vulnerables que denuncian uso discriminatorio. ${ }^{70}$ La verdad, sin embargo, es que en todo este debate no se ha esgrimido ninguna información

${ }^{68}$ Sin la pretensión de arrojar un resultado estadísticamente correcto, sino con la idea de entregar una imagen presento algunos ejercicios para graficar este punto. Ya he dicho que si uno considera el total de la población del año 2014, el total de controles de identidad superaría el 10 por ciento de la población. Esa cifra se incrementa de manera significativa cuando se reduce el universo de las personas a considerar como potenciales controlados, si es que sólo consideramos como parte del universo a quienes tienen "riesgo serio" de ser controladas. En esta dirección, si excluimos a los niños más pequeños o a los adultos que pertenecen a edades superiores en donde la tasa de criminalidad es mucho más baja y nos focalizamos en que el universo probable objeto de control está en la población de entre 15 y 45 años de edad (8.354.966, según los datos del Instituto Nacional de Estadísticas - INE - del año 2014), tenemos que el 22,2 por ciento de esa población fue potencialmente objeto de control de identidad. Como se puede ver, una cifra que eleva a más del doble del promedio total del país. Si se reduce aún más el universo, considerando que esta facultad se ejerce principalmente en hombres en ese rango de edad (4.215.248, según cifras del INE 2014), el porcentaje de potenciales controlados el 2014 subiría al 44 por ciento del universo total. Hacer afirmaciones más específicas en este punto requeriría contar con datos no disponibles acerca de quiénes son las personas a las que efectivamente se controló la identidad el año 2014. Con todo, este ejercicio muy preliminar muestra que el porcentaje de controlados cambia radicalmente en la medida en que se ajusta el universo. En ese contexto, es muy probable que haya segmentos importantes de la población que tienen porcentajes de controles bajísimos, en tanto que otros sufren más directamente el rigor de su uso. Los datos de población fueron obtenidos de http://www.ine.cl/canales/chile_estadistico/familias/ demograficas_vitales.php.

${ }^{69} \mathrm{La}$ experiencia comparada ratifica esto. "En Reino Unido, la probabilidad de la población negra de ser controlada es 25 veces mayor que la de población blanca. En Nueva York, incluso en barrios donde sólo el 24 por ciento de la población es negra y latina, este grupo representa el 79 por ciento de los controles", afirma Catalina Droppelman, "Control de identidad preventivo y su impacto social", El Mercurio Legal, 22 de junio de 2015.

70 Véase Irarrázabal, "Igualdad en Chile", 242-243. Se trata de un problema de antigua data en nuestro país. Cuando se discutió la derogación de la denominada "detención por sospecha" el año 1998, el debate legislativo dio cuenta de una preocupación importante por el uso de esta institución focalizada en jóvenes marginales. Irarrázabal, "Controles preventivos". 
específica de corte empírico acerca de cómo se usa esta facultad en la actualidad y al parecer ella no es ni siquiera conocida por las propias policías. ${ }^{71}$

Se suma a lo anterior la existencia de bastante evidencia a nivel comparado que sugiere que facultades de este tipo se pueden prestar para abusos policiales y prácticas discriminatorias en contra de jóvenes y personas pertenecientes a sectores sociales más desventajados. ${ }^{72}$

En consecuencia, hay que considerar que la introducción de una facultad de este tipo podría producir un aumento de las privaciones de libertad de corto tiempo, y que, de ser así, ellas se focalizarían en ciertos grupos de personas que se ubican dentro de los estereotipos que la propia policía tiene de quienes son personas "sospechosas". De acuerdo a las cifras que he mostrado previamente, estamos hablando de una cantidad importante de ciudadanos que se exponen a trato discriminatorio.

En ese contexto, la norma aprobada por la Cámara de Diputados ha pretendido hacerse cargo de este problema por la vía de dos estrategias. La primera es regular un inciso especial del artículo 12 (segundo), que establece una exigencia de trato igualitario y no discriminatorio con su uso. ${ }^{73}$ Sin lugar a dudas, se trata de una iniciativa loable, aun cuando insuficiente. De acuerdo a nuestro sistema legal vigente, no debiera ser necesaria una cláusula como ésta para que los órganos del Estado

${ }^{71}$ Irarrázabal describe cómo ha solicitado sin éxito a Carabineros de Chile, utilizando la Ley de Transparencia, datos sobre la edad, sexo y nacionalidad de las personas sometidas a control de identidad. También relata que dicha información no ha sido obtenida por no estar sistematizada, y en los pocos datos que se le han entregado, el propio Consejo para la Transparencia los ha calificado como "datos inexactos", ya que, por ejemplo, un número importante de personas controladas figuran con edades de cero o superiores a los noventa años de edad. Irarrázabal, "Controles preventivos".

72 Para el caso del Reino Unido, puede verse: Equality and Human Rights Commission, "Stop and Think: a critical review of the use of stop and search powers in England and Wales", 2010, en www.equalityhumanrights.com/ e Irarrázabal, "Igualdad en Chile", 247-256. Para el debate en los Estados Unidos, específicamente en Nueva York, puede verse Jeffrey Toobin, "The last word in stop and frisk?", The New Yorker, 11 de noviembre de 2013, en http://www.newyorker.com/news/ daily-comment/the-last-word-on-stop-and-frisk. Críticas de esta misma naturaleza también se formulan en países como España, Francia y Holanda, entre otros. Ver Bradford et al., The SAGE.

${ }^{73}$ El tenor literal de dicha regla es: "En la práctica de la identificación se deberán respetar la igualdad de trato y no discriminación arbitraria”. 
tengan deberes de trato igualitario y no discriminatorio. Los problemas, especialmente en una facultad como ésta, no vienen de la falta de regulación normativa de la igualdad, sino más bien de los incentivos y dinámicas que en la práctica llevan a comportamientos que vulneran tal principio. En ese contexto, el principal problema sigue siendo el entregar a las policías una facultad extremadamente abierta sin sujeción a límites o reglas que obliguen a justificar su decisión de controlar la identidad.

La segunda estrategia ha sido la de regular una obligación a las policías de crear un procedimiento de reclamo para quienes estimen han sido objeto de un uso arbitrario de esta facultad, como también la publicación de dicha información y su entrega periódica de sus estadísticas a las autoridades. ${ }^{74}$ Nuevamente se trata de medidas bien inspiradas, que podrían incluso agregarse al actual artículo 85 del CPP. Con todo, es difícil que per se resuelvan el problema de uso desigual o discriminatorio de una facultad de este tipo. ${ }^{75}$ En este sentido, la directora del Instituto Nacional de Derechos Humanos ha manifestado su preocupación respecto al proyecto, apuntando que el contexto institucional de falta de controles internos y externos a las policías no asegura que el uso de esta facultad no sea discriminatorio. De hecho, concluye: "El resultado, entonces, será el de la estigmatización de ciertos grupos de personas vulnerabilizados, como son los jóvenes, los trabajadores y las comunidades mapuches". ${ }^{76}$

\subsection{Riesgos y problemas para el mejoramiento del trabajo policial}

Junto con lo anterior, la introducción de una facultad de este tipo va a hacer un flaco favor a la urgente necesidad que tenemos de pro-

${ }^{74}$ Para detalles, ver nota 11.

${ }^{75}$ Irarrázabal ejemplifica el tipo de dinámica que hace poco efectivos los sistemas de denuncias ante la propia policía. Señala: “...es difícil imaginarse a un joven que está acostumbrado a dosis diarias de discriminación y exclusión exigiéndole explicaciones al carabinero que le solicita identificarse, y luego, en caso de considerar que efectivamente fue objeto de un actuar arbitrario, recurriendo a vías formales de reclamo...". Irarrázabal, "Controles preventivos".

${ }^{76}$ Lorena Fríes, "Sobre el control de identidad", La Tercera, 7 de octubre de 2015, en http:/www.latercera.com/noticia/opinion/ideas-y-debates/2015/10/895650319-9-sobre-el-control-de-identidad.shtml. 
fesionalización y mejora de nuestros cuerpos policiales, especialmente Carabineros. Me parece que en la actualidad parte importante de los problemas para llevar a cabo una lucha más eficaz en contra de la delincuencia se explica como consecuencia de la poca sofisticación del trabajo policial. El cambio de esto supone introducir modernizaciones institucionales complejas y mejorar de manera significativa la coordinación y capacidad de trabajo territorial. ${ }^{77}$

Buena parte de la preocupación actual por el delito obedece a que la delincuencia se ha sofisticado en métodos y organización. ${ }^{78}$ Atacar este fenómeno de manera eficiente supone contar con estrategias e investigaciones más sofisticadas, el desarrollo de mayor inteligencia policial y la mejor coordinación y traspaso de información entre policías y Ministerio Público, entre otras. Descansar, en cambio, en el control de identidad preventivo permite a las policías "subsistir" a través del desarrollo de estrategias de muy baja calidad, sin ninguna sofisticación, como, por ejemplo, salir a "pescar" vía controles masivos o "rastrillos". Ese tipo de actividad sin lugar va a generar estadística policial. Si se organizan operativos masivos de control de identidad preventivos lo más probable es que se encuentren cosas, por ejemplo, personas que porten pequeñas cantidades de droga (para su venta o consumo personal). Esos casos darán un número que podrá ser invocado por las policías como un indicador de éxito. Con todo, la pregunta es si esa estadística reflejará un trabajo policial realmente focalizado en los problemas delictuales más relevantes.

Parte importante de la crisis de seguridad que se conoció durante el año 2015 se explica como consecuencia del actuar de pequeños grupos de criminales organizados, que realizan diversos robos violentos y cometen repetidamente tales acciones. Según han reconocido las propias autoridades policiales, se trata de grupos que han aprendido a evitar el control policial, por ejemplo, utilizando autos de lujo para cometer sus delitos o interviniendo de manera muy rápida en lugares en donde han

${ }^{77}$ Ver Mertz, "Paz Ciudadana refuta".

${ }^{78}$ En esta dirección, por ejemplo, el senador Espina señala en una entrevista: "Los delincuentes inventan nuevas formas de asalto y robos que son cada vez más arriesgadas". "Víctima de 'portonazo' que fue arrastrada por la calle quedó con riesgo vital”, La Tercera, 29 de agosto de 2015, 21. 
constatado que no hay vigilancia. ${ }^{79}$ En ese escenario, la facultad de control preventivo de identidad ayuda poco o nada. El problema, eso sí, es que permite sustentar el trabajo policial en "barridas masivas" de personas con poco impacto en los delitos más graves y con serios riesgos para los derechos ciudadanos. A mediano y largo plazo la única forma de tener un combate fuerte y decidido en contra de la delincuencia pasa por mejorar la capacidad profesional de nuestras policías y del sistema de justicia criminal en su conjunto. La facultad de control de identidad preventivo apunta exactamente en la dirección contraria.

\section{A MODO DE CONCLUSIÓN}

Desde el inicio del debate público, los promotores de instaurar un control de identidad preventivo en nuestro país construyeron un discurso de justificación de esta facultad basado en un desconocimiento muy notorio de la evidencia empírica disponible, de sus consecuencias negativas para los derechos de las personas y de los alcances de facultades similares contempladas en el derecho comparado. A pesar de todos estos defectos, pudieron instalar en el debate público la noción de que se trataba de una reforma indispensable para la seguridad ciudadana, inocua desde el punto de vista de los derechos ciudadanos, ampliamente reconocida en el derecho comparado y que sólo era rechazada por grupos minoritarios radicales en el país o por grupos de personas preocupadas por defender a delincuentes. ${ }^{80} \mathrm{Su}$ éxito fue tal que, a pesar de todos los defectos que he descrito, lograron contar con el apoyo del Poder Ejecutivo en la tramitación del proyecto, que se había mostrado reacio en sus inicios y, finalmente, obtuvieron su aprobación en la Cá-

${ }^{79}$ En esta dirección se han orientado las propuestas de Carabineros en materia de seguridad pública. "Refuerzo antidelito en Carabineros incluye metas: desactivar 24 bandas en 90 días", El Mercurio, 3 de agosto de 2015, C7.

${ }^{80}$ Un ejemplo notable de este último punto se dio a propósito de una polémica generada entre los diputados Fuenzalida y Cariola, al momento de aprobarse esta facultad en la Comisión de Seguridad Ciudadana de la Cámara de Diputados. En esa oportunidad, Fuenzalida publicó un tuit que celebraba la aprobación del proyecto que contó con el rechazo de Cariola, señalando: "Los delincuentes pueden estar tranquilos tienen una representante en el Congreso: la diputada Karol Cariola". "Polémica en twitter entre diputados Fuenzalida y Cariola por control de identidad preventivo", La Tercera, 6 de mayo de 2015. 
mara de Diputados. Visto entonces desde la perspectiva de quién gana o pierde en el debate legislativo, ellos sin lugar a dudas se han apuntado una victoria.

A pesar de este éxito, me parece que la evaluación final de quién gana o no con un proyecto de este tipo debe hacerse desde un punto de vista un poco distinto. La pregunta relevante es si como sociedad podremos estar mejor, es decir, si una facultad de este tipo podrá cumplir efectivamente con las enormes expectativas que sus promotores han ofrecido, y ello sin afectar de manera importante los derechos de las personas. Desde ese punto de vista, más amplio, me parece que estamos en presencia de una clara derrota al interés público. Durante el desarrollo del trabajo he intentado demostrar que la falta de calidad del debate legislativo ha permitido avanzar con una propuesta que no tiene posibilidades reales de tener un impacto relevante en mejorar los niveles de seguridad ciudadana y, en cambio, sí puede producir riesgos importantes para los ciudadanos, así como deteriorar la calidad del trabajo policial.

Junto con lo anterior, también me parece que estamos en presencia de una derrota a las expectativas de racionalidad y calidad que se debiera esperar en el debate legislativo. Al parecer, los temas vinculados a seguridad ciudadana ponen una presión demasiado intensa en nuestros legisladores para fijarse, al momento de discutir y aprobar los proyectos, en "finezas" argumentativas como son los datos de la realidad que se intenta regular y cambiar.

La seguridad ciudadana es un tema demasiado importante como para seguir descansando en respuestas legislativas basadas en la intuición o prejuicios y con fundamentos tan precarios como los invocados en este caso. Espero que este trabajo sirva como un llamado de alerta para elevar el nivel del debate en ésta y otras materias que a futuro se discutirán en el área. Para ello debemos tratar de evitar el uso de etiquetas maniqueas que se instalan en el debate público. Manifestar una oposición a regular el control de identidad preventivo no es equivalente a "apoyar a la delincuencia", sino, más bien, una opción por buscar soluciones más racionales y efectivas a los problemas reales que tiene el funcionamiento de nuestro sistema de justicia penal. Por ejemplo, estimo que hoy podría existir efectivamente un vacío legal importante en materia de regulación de las facultades policiales respecto a su acti- 
vidad fuera del ámbito de una investigación penal. Por lo mismo, creo sería necesario discutir un estatuto que se haga cargo de un conjunto de problemas que la práctica presenta al trabajo policial en áreas tan disímiles como el control de espacios públicos o la atención de situaciones conflictivas de calle no constitutivas de delito. Por otra parte, debiera también concentrarse la regulación de este tipo de facultades en un estatuto normativo claro, y evitar así cierta dispersión existente en la actualidad, facilitando con ello una interpretación y uso adecuado de parte de las fuerzas policiales. Avanzar en esta dirección supone que tengamos un debate serio (que entre otras cosas cuente con buenos fundamentos empíricos y no se base sólo en intuiciones o percepciones), que nos permita identificar en dónde están las carencias principales y cómo ellas podrían resolverse con normas que equilibren adecuadamente los valores en juego. Pretender resolver estas carencias mediante una norma tan deficitaria y con tan poco fundamento como la de control de identidad preventivo no es la vía adecuada.

\section{BIBLIOGRAFÍA CITADA}

\section{Libros, artículos académicos y capítulos de libros}

Bradford, Ben, Beatrice Jauregui, Ian Loader \& Jonny Steinberg, eds. The SAGE Handbook of Global Policing. London: SAGE, en prensa para 2016.

Calland, Shelli. "Hiibel v. Sixth Judicial District Court: Stop and Identity Statutes Do Not Violate the Fourth or Fifth Amendments". Harvard Civil Rights-Civil Liberties Law Review 40 (2005): 251-263.

Casal Hernández, Jesús María. Derecho a la libertad personal y diligencias policiales de identificación. Madrid: Centro de Estudios Políticos y Constitucionales, 1998.

Dressler, Joshua. Understanding Criminal Procedure. New York: Mathew Bender, 1998.

Duce, Mauricio. "La 'reforma a la reforma procesal penal': análisis de la gestación y contenidos de un proyecto de ley”. En Anuario de derecho público 2013. Santiago: Ediciones Universidad Diego Portales, 2013.

Hernández, Héctor. "La detención declarada ilegal y sus consecuencias sobre las medidas cautelares y el régimen de exclusión de prueba". En Agenda corta antidelincuencia. Santiago: Centro de Documentación de la Defensoría Penal Pública, 2010.

Irarrázabal, Paz. "Igualdad en Chile: el caso del control de identidad". Revista Política Criminal 10 (julio 2015): 235-65. 
Koclanes, Peter. 'Unreasonable Seizure: 'Stop and Identity' Statutes Create an Illusion of Safety By Sacrificing Real Privacy". Florida Law Review 57 (2005): 431-44.

Rabi, Roberto. “¿Qué rol y justificación tiene el control de identidad de una persona en nuestro sistema procesal penal considerando el actual texto del artículo 85 del Código Procesal Penal”. Revista Estudios de la Justicia 13 (2010): 323-63.

Ramos, César. "Control de identidad. Bases para una aplicación diferenciada del artículo 85 del Código Procesal Penal". En Diez años de la reforma procesal penal en Chile. Santiago: Ediciones Universidad Diego Portales, 2011.

Ramos, César \& María Merino. "Control de identidad". Memoria para la obtención del grado de licenciado en ciencias jurídicas y sociales. Santiago, Universidad de Chile, 2010.

Roxin, Claus. Derecho Procesal Penal. Buenos Aires: Editores del Puerto, 2003.

Salas, Jaime "Evolución del control de identidad. ¿En ruta a su desnaturalización?". En Problemas del Proceso Penal. Santiago: Librotecnia, 2015.

\section{Opiniones y textos seleccionados en medios de prensa}

Droppelman, Catalina. "Control de identidad preventivo y su impacto social". El Mercurio Legal. 22 de junio de 2015.

Farcas, Daniel. "Control de identidad preventivo: ¿Detención por sospecha?”. E-pistolas, El Mostrador. 2 de septiembre de 2015: "Control de identidad preventivo: ¿detención por sospecha?”. http://e-pistolas.org/debate/control-deidentidad-preventivo.

Frey, Antonio. "Control de identidad preventivo: más seguridad sin vulnerar los derechos de las personas". El Mostrador. 19 de septiembre de 2015.

Fríes, Lorena. "Sobre el control de identidad". La Tercera, 7 de octubre de 2015.

Fuenzalida, Gonzalo. "Control preventivo de identidad". Carta al director. El Mercurio, 29 de mayo de 2015, A2.

Greene, Pía. "Más evidencia menos intuición”. La Tercera, 28 de julio de 2015.

Irarrázabal, Paz. "Controles preventivos y la amenaza para la igualdad". El Mostrador. 18 de septiembre de 2015.

Matus, Jean Pierre. "Control de identidad, sistema acusatorio y Estado de Derecho". El Mercurio Legal. 9 de octubre de 2015.

Mertz, Catalina. "Paz Ciudadana refuta al Gobierno por delincuencia: 'Si no hubiese delitos no habría sensación de temor'”. EMOL. 28 de julio de 2015. http://www.emol.com/noticias/Nacional/2015/07/28/740298/Paz-Ciudadanarefuta-al-Gobierno-por-delincuencia-Si-no-hubiese-delitos-no-habriasensacion-de-temor.html.

Nogueira, Claudia. "Control de identidad". Carta al director. La Tercera, 25 de mayo de 2015. http://diario.latercera.com/2015/05/25/01/contenido/ opinion/11-190343-9-control-de-identidad.shtml. 
_. "Control de identidad". Carta al director. La Tercera, 2 de junio de 2015. http://diario.latercera.com/2015/06/02/01/contenido/opinion/11-190918-9control-de-identidad.shtml.

Pavez, Máximo. “El que nada hace...”. La Tercera. 23 de mayo de 2015. http:// www.latercera.com/noticia/opinion/ideas-y-debates/2015/05/895-630898-9-elque-nada-hace.shtml.

—. "Control de identidad preventivo: ¿por qué temer?". La Tercera. 25 de agosto de 2015. http://voces.latercera.com/2015/08/25/maximo-pavez/controlde-identidad-preventivo-por-que-temer.

Toobin, Jeffrey. "The last word in stop and frisk?". The New Yorker, 11 de noviembre de 2013. http://www.newyorker.com/news/daily-comment/the-lastword-on-stop-and-frisk. EP 